\title{
Correction to: Two-Stage Versus One-Stage Nipple-Sparing Mastectomy: Timing of Surgery Prevents Nipple Loss
}

Tammy Ju, MD ${ }^{1}$, Julia Chandler, MD¹, Arash Momeni, $\mathrm{MD}^{2}$, Geoffrey Gurtner, $\mathrm{MD}^{2}$, Jacqueline Tsai, MD ${ }^{1}$, Dung Nguyen, $\mathrm{MD}^{2}$, and Irene Wapnir, $\mathrm{MD}^{1}$

${ }^{1}$ Section of Surgical Oncology, Department of Surgery, Stanford University School of Medicine Stanford, Stanford, CA; ${ }^{2}$ Division of Plastic Surgery, Department of Surgery, Stanford University School of Medicine Stanford, Stanford, CA

CORRECTION TO: ANN SURG ONCOL HTTPS://DOI.ORG/10.1245/S10434-021-10456-6

The article title is correct as reflected here. The original article has been updated.
Publisher's Note Springer Nature remains neutral with regard to jurisdictional claims in published maps and institutional affiliations.

The original article can be found online at https://doi.org/10.1245/ s10434-021-10456-6.

(C) Society of Surgical Oncology 2021

Published Online: 2 August 2021

I. Wapnir, MD

e-mail: wapnir@stanford.edu 